\title{
PENANGANAN DAMPAK LALU LINTAS TERHADAP PEMBANGUNAN PASAR TRADISONAL DAN PASAR MODERN (MALL) SIMPANG HARU
}

\section{HANDLING TRAFFIC IMPACT ON DEVELOPMENT AND MARKET MODERN TRADITIONAL MARKETS (MALL) SIMPANG HARU}

\author{
Momon \\ Badan Perencanaan Pembanguna Daerah Provinsi Sumatera Barat \\ J1. Khatib Sulaiman No. 25 Padang \\ e-mail: momon2008@gmail.com \\ Dikirim: 3 Maret 2013; direvisi: 16 April 2013; disetujui: 19 Juni 2013
}

\begin{abstract}
Abstrak
Tujuan penelitian ini adalah Memberikan rekomendasi kepada pemangku kepentingan untuk mengantisipasi kemacetan (penurunan kinerja persimpangan) yang disebakan oleh pengoperasian Pasar Tradisional dan Pasar Modern. Penelitian ini menggunakan analisis kinerja simpang bersimpang MKJI Tahun 1997 dengan memasukkan data primer yaitu data gerakan membelok di persimpangan. Dari hasil analisis dapat disimpulkan bahwa Strategi 1 (satu) dan 2 (dua) dapat meningkatkan kinerja jaringan pada lengan persimpangan yang macet (jl. Sawahan) ditandai dengan DS dari 1.03 meter menjadi 0.66 meter dan 063 meter, Panjang Antrian dari 199 detil/smp menjadi 173 (strategi 2) dan tundaan dari $142.9 \mathrm{detik} / \mathrm{smp}$ menjadi $28 \mathrm{detik} / \mathrm{smp}$ dan $33 \mathrm{detik} / \mathrm{smp}$.
\end{abstract}

Kata Kunci : Trip Rate, Simpang Bersinyal, Kinerja Persimpangan

\begin{abstract}
The aim of this research is giving recommendation to decision maker For overcoming jammed (decreasing performance intersection) that caused by traditional and modern market operational. This research use intersection performance analysis MKJI 1997 with primary data, turning moving intersection data. From the result of analysis, it can be concluded that first strategy and second strategy can improve network performance in crowded intersection arm (jl. Sawahan) that is revealed by DS from 1.03 metres to 0.66 metres and 0.63 metres, the length of queue from 199 detil/smp to 173 (strategi 2) and cancel time from $142.9 \mathrm{~second} / \mathrm{smp}$ to $28 \mathrm{~second} / \mathrm{smp}$ and $33 \mathrm{~second} / \mathrm{smp}$.

Keyword : Trip Rate, Signal intersection, Performance intersection
\end{abstract}

\section{PENDAHULUAN}

Pembangunan suatu kawasan dan/atau lokasi tertentu mempunyai pengaruh terhadap lalu lintas disekitarnya. Analisis dampak lalu lintas dipergunakan untuk memprediksi apakah infrastruktur transportasi dalam daerah pengaruh pembangunan tersebut dapat melayani lalu lintas yang ada (eksisting) ditambah dengan lalu lintas yang dibangkitkan atau ditarik oleh pembangunan tersebut. Jika prasarana yang ada tidak dapat mendukung lalu lintas tersebut maka harus dilakukan kajian penaganan prasarana dan pengaturan manajemen lalu lintas.

Bila ditinjau dari aspek hukum dengan diterbitkannya Undang-Undang Nomor 22 tahun 2009 pasal 99 yang berbunyi 'setiap rencana pembangunan pusat kegiatan, permukiman, dan infrastruktur yang akan menimbulkan gangguan Keamanan, Keselamatan, Ketertiban, dan Kelancaran Lalu Lintas dan angkutan Jalan wajib dilakukan analisis dampak Lalu Lintas', adanya kewajiban yang diamanatkan oleh undang-undang akan ditindaklanjuti dengan proses pengawasan dan monitoring oleh pemerintah. maka tidak bisa dihindari lagi pelaksanaan andalalin pembangunan Pasar Tradisional dan Modern Simapng Haru harus dilakukan oleh pengembang.

Secara umum telah diterima suatu konsep analisis "menginternalkan eksternalitis" dengan konsekuensi "poluter pays" dengan pengertian bahwa pihak pengembang harus memberikan kontribusi yang nyata di dalam penanganan dampak lalu lintas sebagai akibat pengembangan suatu kawasan atau lokasi tertentu.

Rencana Pembangunan Pasar Tradisional dan Modern Simpang Haru yang merupakan pusat kegiatan perbelanjaan yang terletak pada Jalan Simpang Haru menjadi kawasan pembangkit dan penarik lalu lintas. Hal ini berdampak terhadap penambahan pembebanan lalu lintas oleh kendaraan pribadi maupun sepeda motor yang akan keluarmasuk pusat kegiatan. Pembebanan lalu lintas baru akibat pembangunan Pasar tersebut secara langsung membawa penurunan kinerja jaringan jalan di sekitar lokasi pembangunan. Oleh karena itu diperlukan Analisis Dampak Lalu Lintas dan Upaya Manajemen 
serta Rekayasa Lalu Lintas untuk meminimumkan dampak tersebut.

Perumusan masalah dalam penelitian adalah seberapa besar penurunan kinerja persimpangan akibat pembangunan Pasar Tradisiional dan Pasar Modern di Simpang Haru dan apa stragi yang digunakan untuk meingkatkan kinerja persimpangan Tujuan Penelitian ini adalah sebagai berikut:

1. Mengevaluasi pengaruh kinerja lalu lintas yang ditimbulkan dengan keberadaan pembangunan Pasar Tradisional dan Modern Simpang Haru tersebut

2. Meminimumkan dampak yang terjadi terhadap kinerja persimpangan.

3. Memberikan rekomendasi kepada pemangku kepentingan untuk mengantisipasi kemacetan (penurunan kinerja persimpangan) yang disebakan oleh pengoperasian Pasar Tradisional dan Pasar Modern. perkantoran baru, pabrik, pusat perbelanjaan dan lain sebagainya. Perubahan tata guna tanah bisa meliputi pengembangan ulang dari daerah saat ini menjadi daerah yang peruntukkannya campuran.

Studi dampak lalu lintas memproyeksikan permintaan transportasi yang akan datang, menilai dampak perubahan dari permintaan dan sebagainya. Untuk studi ini, permintaan transportasi didefinisikan sebagai kebutuhan pergerakan orang dan barang oleh seluruh bentuk transportasi meliputi mobil, truk, motor, sepeda, taksi, angkutan kota di sekitar usulan pengembangan.

\section{Perencanaan Transportasi}

Di dalam perencanaan sektor transportasi perlu ada pendekatan umum dalam proses perencanaan, dimana semua faktor yang terkait dianalisis sesuai dengan permasalahan yang ada. Menurut Black (1981), ada beberapa langkah (pendekatan sistem) proses perencanaan pada Gambar 1 .

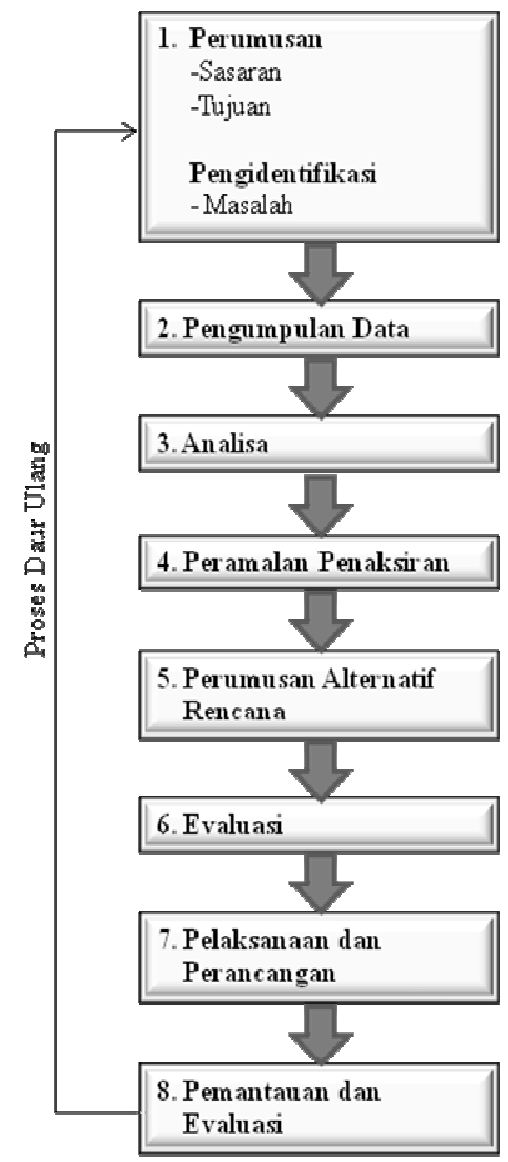

Gambar 1. Proses Perencanaan Transportasi.

\section{Analisis Mengenai Dampak Lalu Lintas}

(AMDALL)

Analisis Mengenai Dampak Lalu Lintas (AMDALL) merupakan suatu studi penilaian dampak transportasi akibat dari usulan pengembangan dan perubahan tata guna tanah. Pengembangan tersebut dapat berupa suatu gedung
Menurut Papacostas (1987), transportasi merupakan sebuah fasilitas yang dapat mengatasi hambatan ruang yang dialami manusia dan barang dalam melakukan berbagai aktivitas untuk pemenuhan kebutuhan hidup manusia. Sedangkan tujuan perencanaan transportasi lebih pada proses 
prediksi permintaan transportsi dalam menyusun alternatif pemecahan masalah.

Persimpangan dengan Lampu Lalu Lintas

Didalam Manual Kapasitas Jalan Indonesia (1997), analisis persimpangan dengan lampu lalu lintas didasarkan pada beberapa prinsip utama sebagai berikut :

\section{Geometrik}

Perhitungan dikerjakan secara terpisah untuk setiap pendekat. Satu lengan simpang dapat terdiri dari lebih dari satu pendekat, misalnya dibagi dalan dua atau lebih seu-pendekat. Ini bisa terjadi pada kasus apabila pergerakan belok kanan dan/atau belok kiri menerima sinyal hijau pada fasa yang berbeda daripada lalu lintas lurus, atau jika lengan simpang tersebut dibagi oleh pulau-pulau.

2. Arus Lalu Lintas

Perhitungan dilakukan berdasarkan lalu lintas jam-jaman untuk satu atau lebih perioda, didasarkan pada arus lalu lintas rencana jam puncak untuk kondisi pagi, siang atau sore hari. Arus lalu lintas (Q) untuk setiap pergerakan (belok kiri, lurus dan belok kanan) dikonversikan dari kendaraan per jam ke satuan mobil penumpang (smp) per jam dengan menggunakan ekivalen mobil penumpang( emp) untuk jenis pendekat terlindung dan terlawan.

\section{Model Dasar}

Kapasitas pendekat untuk persimpangan dengan lampu lalu lintas dapat dinyatakan sebagai berikut :

$\mathrm{C}=\mathrm{S} \times \mathrm{g} / \mathrm{c}$

dimana :

$\mathrm{C}=$ kapasitas (smp/jam)

$\mathrm{S}=$ arus jenuh (smp/jam hijau)

$\mathrm{g}=$ waktu hijau (detik)

$\mathrm{c}=$ waktu siklus (detik)

4. Waktu Sinyal

Waktu sinyal untuk kondisi pengkontrolan waktu tetap ditentukan berdasarkan Metoda Webster untuk meminimumkan waktu tunda kendaran seluruhnya di persimpangan. Pertamatama waktu siklus ( c ) ditentukan, dan setelah itu waktu hijau pada setiap fasa.

$\mathrm{c}=(1,5 \times \mathrm{LTI}+5) /(1-\Sigma$ Frcrit $)$

dimana :

c = waktu siklus (detik)

LTI = waktu hilang per siklus (detik)

$\mathrm{FR}=$ arus dibagi arus jenuh $(\mathrm{Q} / \mathrm{S})$

Frcrit = nilai tertinggi dari FR dari seluruh pendekat dari suatu fasa sinyal

$\Sigma$ Frcrit $=$ jumlah dari FRcrit dari seluruh fasa pada siklus

5. Kapasitas dan Derajat Kejenuhan

Kapasitas pendekat ( $\mathrm{C}$ ) diperoleh dengan mengalikan arus jenuh dan rasio hijau (g/c) untuk setiap pendekat.

$\mathrm{C}=\mathrm{S} \times \mathrm{g} / \mathrm{c}$
Derajat kejenuhan diperoleh dari persamaan sebagai berikut :

$\mathrm{DS}=\mathrm{Q} / \mathrm{C}=(\mathrm{Q} \times \mathrm{c}) /(\mathrm{S} \times \mathrm{g})$

6. Panjang Antrian

Jumlah rata-rata antrian smp pada awal sinyal hijau (NQ) dihitung sebagai jumlah smp yang tersisa dari fase hijau sebelumnya $\left(\mathrm{NQ}_{1}\right)$ ditambah jumlah smp yang datang selama fase merah $\left(\mathrm{NQ}_{2}\right)$

$\left.\mathrm{NQ}_{=} \mathrm{NQ}_{1}\right)+\left(\mathrm{NQ}_{2}\right)$

7. Tundaaan

$D T=c \times \frac{0,5 \times(1-G R)^{2}}{(1-G R \times D S)}+\frac{N Q_{1} \times 3600}{C}$

Dimana :

DT $=$ Tundaan lalu lintas rata-rata pada pendekat $\mathrm{j}$ (det/smp)

$\mathrm{GR}=$ Rasio hijau (g/c)

$\mathrm{DS}=$ Derajat kejenuhan

$\mathrm{C}=$ Kapasitas (smp/jam

$\mathrm{NQ}=$ Jumlah smp yang tertinggal dari fase hijau sebelumnya

\section{METODE PENELITIAN}

\section{Jenis dan Sumber Data}

Data yang telah dikumpulkan baik yang melalui survey sebagai data primer maupun data sekunder. Data primer yang telah dikumpulkan adalah data volume lalu lintas yang terklasifikasi di persimpangan. Mulut persimpangan yang dilakukan survey antara mulut persimpangan jalan SawahanJalan Sutomo-Jalan Andalas. Selain itu juga dilakukan pengumpulan data keluar masukk kendaraan dan orang di Pasar Simpang haru .

Data sekunder yang telah dikumpulkan adalah data mengenai luas tanah Pasar Tradisional dan Modern Simpang Haru dan peruntukkannya, luas bangunan/ruang dan peruntukkannya.

\section{Pengumpulan Data}

\section{Data Primer}

Pengumpulan data primer dilakukan dengan melakukan perhitungan gerakan kendaraan membelok, baik yang belok kanan, lurus maupun belok kiri. Pencacahan dilaksanakan dengan menggunakan tenaga surveyor yang ditempatkan mulut persimpangan. Untuk kendaraan yang keluar masuk kendaraan dan orang dilaksanakan di dekat pintu masuk pasar (eksisting) bagian depan dan dibagian samping pasar.

Pengumpulan data primer ini dilakukan pada hari Minggu dan Senin dengan mengambil pada jam puncak pagi 07.00 - 09.00, siang $11.00-$ 13.00 dan sore 16.00 -18.00. Data arus lalu lintas dan kendaraan dan orang yang keluar 
masuk masuk simpang haru (eksisting) di dihitung untuk setiap 15 menitan.

2. Data Sekunder

Data sekunder diperoleh dari Pengembangan

Pasar Tradisional dan Pasar Moder (Mall)

SImpang Haru. Data yang diperoleh dari pengembang adalah luas tanah, luas lantai beserta peruntukkan, petak took, ruang parker mobil dan sepeda motor.

\section{Analisis Data}

\section{Kondisi Eksisting Persimpangan}

Pembangunan Pasar Tradisional dan Modern Simpang Haru merupakan salah satu pasar satelit di Kota Padang yang berlokasi di Jl. H. Agus Salim Padang dengan titik koordinat $0^{\circ} 56^{\prime} 36.0^{\prime \prime} \mathrm{LS} 100^{\circ}$ 22' 32.0" BT diatas lahan seluas $6.745 \mathrm{~m}^{2}$. Untuk lebih jelasnya lokasi kegiatan dapat dilihat pada gambar 1.

Pasar Tradisional dan Moder simpang haru terletak pada persimpangan jalan Arteri dan Kolektor. Gambar Penampang melintang masingmasing lengan persimpangan dapat dilihat pada gambar 2.

Dari gambar 1 dan 2, menujukkan bahwa persimpangan yang terletak di lokasi pembangunan MALL merupakan simpang yang mempunyai 4 (empat lengan) namun salah satu lengan simpang pada jalan langkiau mempunyai volume lalu lintas tidak begitu besar maka lampu traffic light yang terpasang saat ini hanya 3 (tiga) lengan yaitu lengan persimpangan pada ruas jalan Sawahan, Andalas, Sutomo.

Kondisi fisik simpang tersebut belum

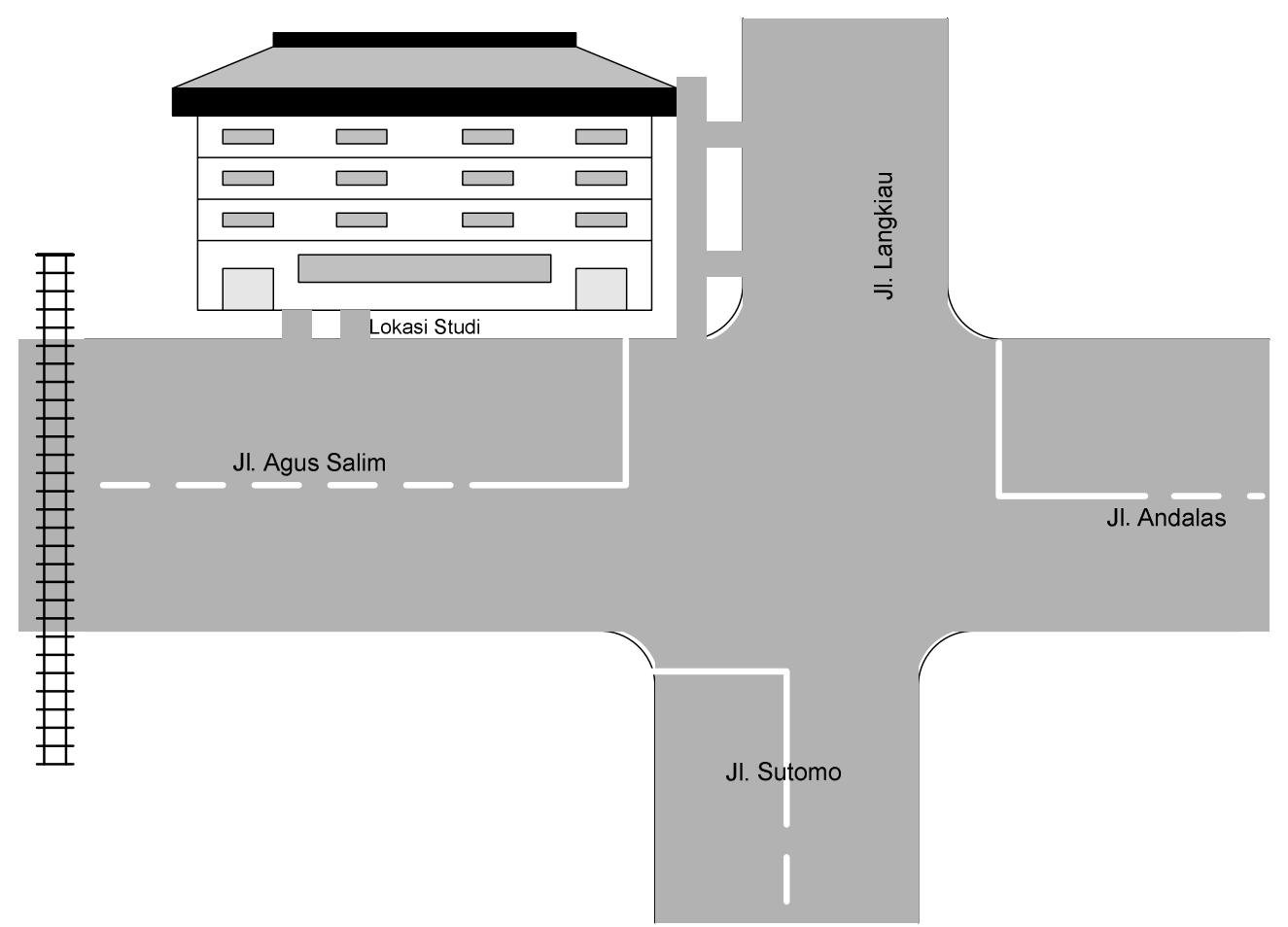

Gambar 1. Kondisi Eksisiting Persimpangan Pada Pembangunan Mall Simpang Haru.

a. Jalan Sawahan

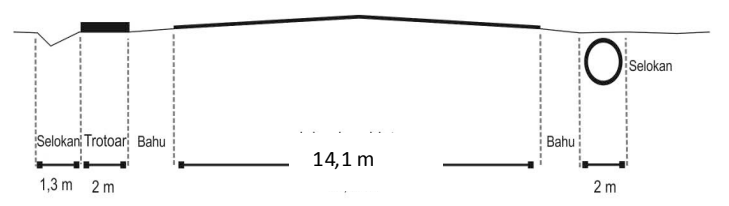

c. Jalan Andalas b. Jalan Sutomo

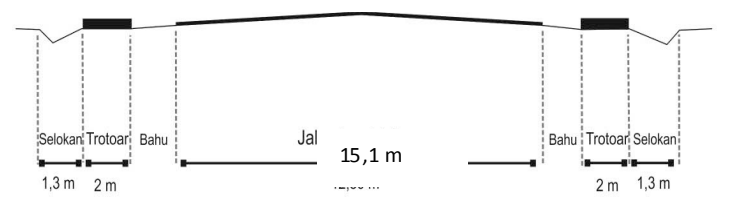

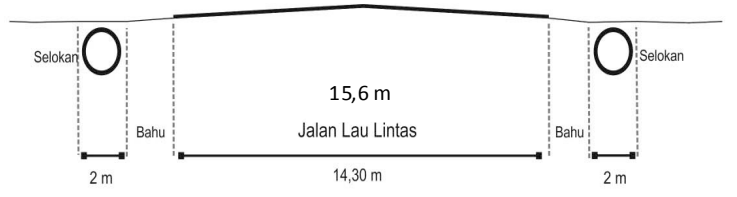


dilengkapi fasilitas separator pada bagian tengah ruas jalan sehingga memungkinkan terjadinya friksi antara jalan yang berlawanan arah, hal ini dapat memperlama delay pada persimpangan. Kondisi perkerasan lengan persimpangan pada ruas jalan langkiau belum dilakukan pemasangan traffic light dan belum dilakukan pengaspalan dengan perkerasan lentur. Apabila Mall Simpan Haru beroperasi maka ruas jalan terjadi peningkatan volume lalu lintas akibat bangkitan dan tarikan yang ditimbulkan oleh Mall tersebut. Hal ini perlu dilakukan rekayasa lalu lintas untuk mengantisipasi kemacetan di persimpangan.

Disamping itu, dilokasi persimpangan juga terlihat minimnya fasilitas kesemalatan seperti rambu larangan berhenti, rambu larangan parkir, rambu tempat prmberhentian angkot. Hal ini akan menyebabkan pengemudi kendaraan bermotor bisa berhenti disembarangan tempat sehiingga menimbulkan kemacetan di persimpangan.

Data yang dikumpulkan dari survey gerakan membelok dan bangkitan perjalanan (keluar masuk pasar) selanjutnya dilakukan tabulasi sesuai dengan kebutuhan untuk analisis. Analisis yang dilakukan adalah analisis persimpangan dan bangkitan perjalanan yang disebabkan oleh Pembangunan Pasar Tradisional dan Pasar Modern (Mall) Simpag Haru.

\section{Volume Lalu Lintas di Persimpangan}

Penghitungan volume lalu-lintas di persimpangan dilakukan guna mengetahui kondisi volume jam puncak dimana volume jam puncak menjadi menjadi rancangan perbaikan kineja persimpangan. Adapun volume lalu lintas di persimpangan dapat sebagai berikut:

Bangkitan/Tarikan Pasar Simpag Simpang Haru (Eksisting). Jumlah tarikan perjalanan diambil dari hasil survey tarikan yang dilakukan di pasar simpang

haru. Hasil survey yang digunakan adalah nilai tingkat tarikan perjalanan di Pasar haru pada kondisi exsisting. Dari hasil survey dilakukan diperoleh tarikan perjalanan yang masuk pada pasar simpang haru.

Tabel 1. Jumlah Bangkitan/Tarikan Kendaraan (smp/jam)

\begin{tabular}{cccc}
\hline & \multicolumn{3}{c}{ Waktu Perjalanan } \\
& Pagi & Siang & Sore \\
\hline $\begin{array}{c}\text { Jumlah } \\
\text { Perjalanan } \\
\text { (smp/jam) }\end{array}$ & 41.5 & 51,75 & 42,5 \\
\hline
\end{tabular}

Sumber : Hasil Analisa

Dari tabel diatas menunjukkan bahwa bangkitan dan tarikan yang tertinggi pada pasar simpang haru terjadi pada siang hari yaitu pada jam $11.00 \mathrm{Wib}-$ 12.00 Wib. Dari hasil perhitungan, jumlah perjalanan tarikan pada pasar simpang haru sebesar 51,75 smp/jam untuk siang. Untuk peak pagi sebesar 41,5 smp/jan dan peak sore 42,5 smp/jam. Jika dibandingkan dengan jumlah petak toko yang beroperasi di pasar simpang haru maka diperoleh trip rate pada saat jam sibuk. Saat sekarang petak toko yang beroperasi pada pasar simpang haru diperkirakan sebesar 90 petak toko. Dari jumlah tersebut maka dapat diperoleh trip rate sebaga berikut :

Tabel 2. Trip Rate Pasar Simpang Haru (Kondisi Eksisting)

\begin{tabular}{cccc}
\hline \multirow{2}{*}{ No } & \multicolumn{3}{c}{ Waktu Perjalanan } \\
\cline { 2 - 4 } & Pagi & Siang & Sore \\
\hline Trip rate & 0,46 & 0,57 & 0,47 \\
\hline
\end{tabular}

Sumber : Hasil Analisa

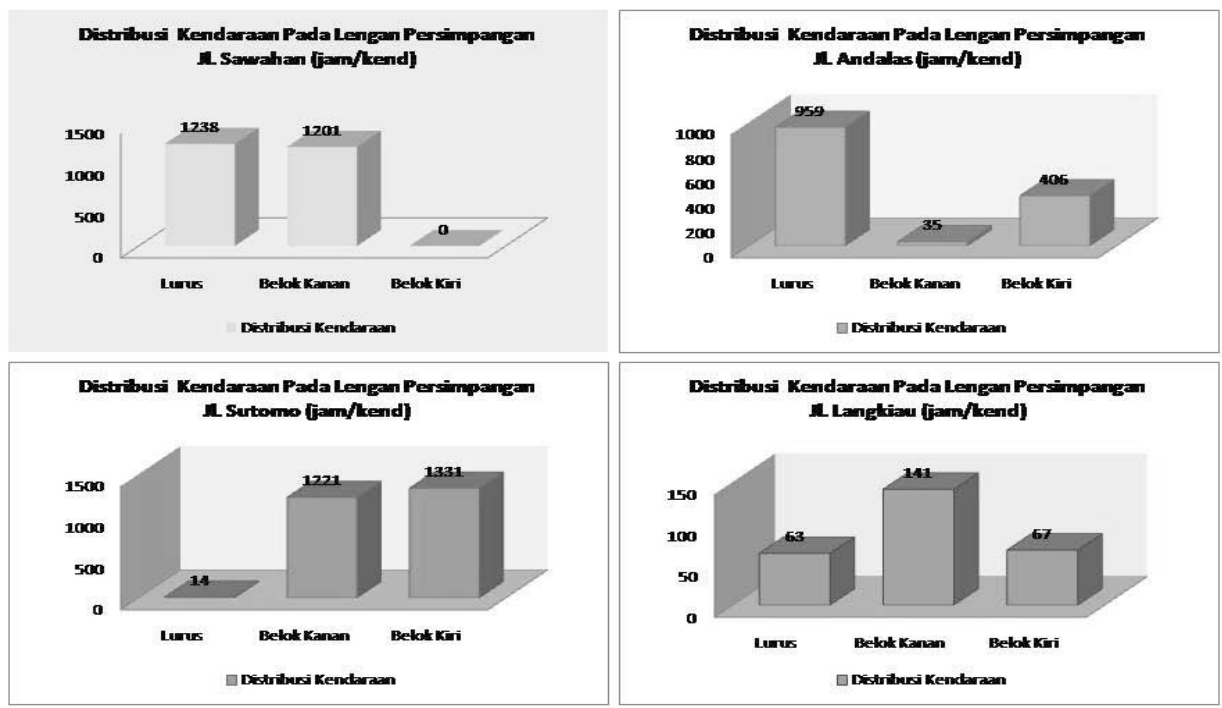

Gambar 2. Distribusi Kendaraan Pada Lengan Persimbangan (kend/jam) Bangkitan/Tarikan Perjalanan 
Tabel 3. Tambahan Perjalanan Pada Saat Pasar Tradisional dan Modern Beroperasi

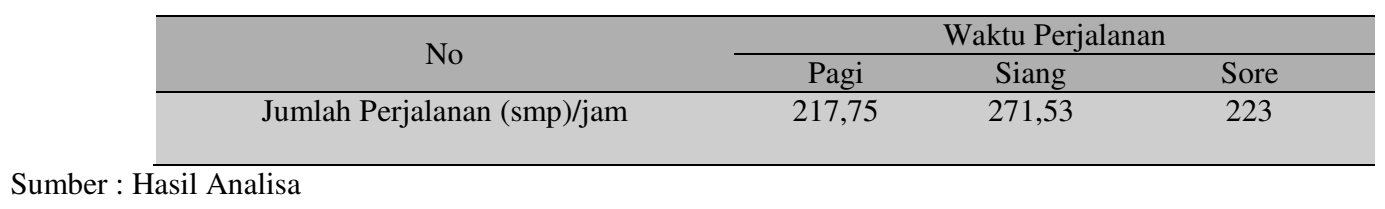

Tabel 4. Volume Persimpangan Jam Puncak sore (smp/jam) Tahun 2013

\begin{tabular}{lccc}
\multicolumn{1}{r}{ Lengan Persimpangan } & \multicolumn{3}{c}{ Volume Jam Puncak (Terlindung) } \\
& Lurus & Belok Kanan & Kiri \\
\hline Jl. Sawahan & 579 & 505 & 0 \\
Jl. Andalas & 419 & 9 & 193 \\
Jl. Sutomo & 14 & 413 & 606 \\
Jl. Langkiau & 44 & 40 & 21 \\
\hline
\end{tabular}

Sumber : Hasil Analisa

Tabel 5. Volume Persimpangan Jam Puncak sore (smp/jam) Tahun 2013

\begin{tabular}{lccc}
\hline \multicolumn{1}{c}{ Lengan Persimpangan } & \multicolumn{3}{c}{ Volume Jam Puncak (Terlawan) } \\
& Lurus & Belok Kanan & Kiri \\
\hline J1. Sawahan & 739 & 679 & 0 \\
J1. Andalas & 485 & 16 & 246 \\
J1. Sutomo & 616 & 6 & 787 \\
J1. Langkiau & 49 & 65 & 32 \\
\hline
\end{tabular}

Sumber : Hasil Analisa

Tabel 6. Kinerja Persimpangan Kondisi Eksisiting Tahun 2013

\begin{tabular}{ccccc} 
No & Lengan Simpang & $\begin{array}{c}\text { Derajat } \\
\text { Kejenuhan }\end{array}$ & $\begin{array}{c}\text { Panjang Antrian } \\
(\mathrm{m})\end{array}$ & $\begin{array}{c}\text { Tundaan rata-rata } \\
(\text { det/smp) }\end{array}$ \\
\hline 1 & 2 & 3 & 4 & 5 \\
1 & Lengan Sutomo (S) & 0.51 & 61.00 & 29.50 \\
2 & Lengan Sawahan (B) & 0.89 & 104.00 & 53.10 \\
3 & Lengan Andalas (T) & 0.50 & 58.00 & 29.40 \\
\hline
\end{tabular}

\section{Sumber : Hasil Analisa}

Jika 446 petak toko yang dibangun oleh pada Pasar Tradisional dan Modern tersebut maka diperoleh hasil jumlah perjalanan yang akan masuk pada tersebut. Dari hasil perhitungan maka diperoleh hasil pada tabel 3 .

Dari tabel diatas menunjukkan bahwa perkiraan total tarikan yang tertinggi pada pasar tradisional dan pasar moder simpang haru terjadi pada siang hari sebesar 271,53 smp/jam. Untuk peak pagi sebesar 217,75 smp/jam dan peak sore 223 smp/jam. Tambahan perrjalanan ini dimasukan pada volume lalu lintas tahun 2014 s/d 2018 ketikan pasar tersebut beroperasi. Jumlah perjalanan yang dimasukan adalah perjalanan pada sore hari karena jam puncak pada saat jam survei adalah sore hari

\section{Kinerja Arus Lalu Lintas Di Persimpangan}

Data-data persimpangan dan bangkitan dan tarikan yang telah dilakukan pengolahan, menjadi dasar untuk melihat kinerja persimpangan baik sebelum dan sesudah pengoperasian Pasar Tradisional dan PAsar Modern. Ukuran kinerja persimpangan adalah perbandingan volume dan kapasitas (DS), Tundaan dan Panjang Antrian.

\section{Kinerja Persimpangan Eksisting (Tahun} 2013)

Berdasarkan hasil survey traffic counting pada periode waktu untuk perancangan adalah jam 17.00 - $18.00 \mathrm{Wib}$, volume lalu lintas yang telah dikonversikan kedalam smp/jam dapat dilihat pada Tabel 4.

Pada mulut persimpangan jalan SawahanJalan Sutomo-Jalan Andalas mempunyai pemfasean dengan 3 (tiga) fase. Sedangkan 
waktu siklus yang diberlakukan pada persimpangan tersebut adalah 91 detik. Dari waktu fasesebut maka dapat diketahui kinerja lalu lintas pad kondisi eksisting

2. Kondisi Kinerja Persimpangan Simpang Haru (Tabel 6)

3. Volume Lalu Lintas Pada Lengan Persimpangan Jam Puncak sore (smp/jam) Tahun 2014 s/d 2018.

Jika terjadi pertumbuhan kendaraan yang melawati jalan Pasar Tradisional dan Modern 3 $\%$ (lima persen) per tahun, maka kondisi 5 tahun mendatang setelah Pasar Tradisional dan Modern selesai dan dioperasikan akan meningkat, kondisi dan volume lalu-lintas di ruas jalan Pasar Tradisional dan Modern diperkirakan seperti berikut;

$\mathbf{P t}=\mathbf{P o}(\mathbf{1}+\mathbf{i})^{\mathrm{n}}$

di mana:

$\mathrm{Pt}=$ Volume Lalu-lintas tahun rencana .

Po $=$ Volume Lalu-lintas tahun target

I = Tingkat pertumbuhan.

$\mathrm{n}=$ Tahun rencana.

Dari persamaan tersebut di atas, maka pembebanan terhadap ruas jalan Pasar Raya dapat diketahui sebagaimana Tabel 6.

Jika dilakukan perhitungan dengan menggunakan data proyeksi dari 2014 s/d 2018, maka dengan menggunakan pemfasean 3 (tiga) dan waktu siklusnya 91 detik maka dampak kinerja persimpangan akibat pembangunan Pasar Tradisonal dan Pasar Modern (Mall) adalah sebagai berikut Lampiran Tabel 7.

\section{Strategi Penanganan}

Untuk mengantisipasi dampak buruknya kinerja persimpangan pada 5 tahun yang akan datang maka dilakukan beberapa strategi-strategi penanganan untuk mengantisipasi dampak adalah sebagai berikut :

1. Strategi 1 (pertama)

Pada strategi 1 (pertama) perbaikan yang dilakukan adalah :

- Melakukan sterilisasi ruas jalan sawahan dari parkir on street sehingga menambah lebar efektif jalan

- Mengatur fase persimpagan dengan menerapkan 4 (empat) fase untuk menghindari resiko kecelakaan

- Waktu siklus 120 detik

- Melakukan pemasangan traffic light pada lengan persimpangan jalan langkiau.

2. Strategi 2 (kedua)

Pada strategi 1 (pertama) perbaikan yang dilakukan adalah :

- Melakukan sterilisasi ruas jalan sawahan dari parkir on street sehingga menambah lebar efektif jalan

- Mengatur fase persimpagan dengan menerapkan 3 (tiga) fase dengan menerapkan early cut off pada mulut persimpangan sawahan dan andalas

- Waktu siklus 120 detik

- Melakukan pemasangan traffic light pada lengan persimpangan jalan langkiau.

Dari hasil perhitungan pada persimpangan bersinyal pasar simpang, maka dapat diketahui Sebelum dan Sesudah pengoperasian Pasar Tradisional dan Pasar Modern (Mall) Simpang Haru pada Tahun 2018. Adapun hasilnya adalah sebagai berikut :

Tabel 8. Perbandingan Kinerja Lalu Lintas Sebelum Pengoperasian dan Setelah Pengoperasian Beserta Penanganan

\begin{tabular}{|c|c|c|c|c|c|c|c|c|c|c|}
\hline \multirow{4}{*}{ No } & \multirow{4}{*}{$\begin{array}{l}\text { Lengan } \\
\text { Simpang }\end{array}$} & \multirow{2}{*}{\multicolumn{3}{|c|}{ Sebelum Pengoperasian }} & \multicolumn{6}{|c|}{ Setelah Pengoperasian } \\
\hline & & & & & \multicolumn{3}{|c|}{ Strategi 1 (pertama) } & \multicolumn{3}{|c|}{ Strategi 2 (Kedua) } \\
\hline & & \multirow[b]{2}{*}{ DS } & \multirow{2}{*}{$\begin{array}{l}\text { Panjang } \\
\text { Antrian } \\
\text { (m) }\end{array}$} & \multirow{2}{*}{$\begin{array}{l}\text { Tundaan } \\
\text { Rata-Rata } \\
\text { (det/smp) }\end{array}$} & & Panjang & Tundaan & & Panjang & Tundaan \\
\hline & & & & & DS & $\begin{array}{l}\text { Antrian } \\
\text { (m) }\end{array}$ & $\begin{array}{l}\text { Rata-Rata } \\
\text { (det/smp) }\end{array}$ & DS & $\begin{array}{l}\text { Antrian } \\
\text { (m) }\end{array}$ & $\begin{array}{l}\text { Rata-Rata } \\
\text { (det/smp) }\end{array}$ \\
\hline 1 & 2 & 4 & 5 & 6 & 7 & 8 & 10 & 11 & 12 & 13 \\
\hline 1 & $\begin{array}{l}\text { Lengan } \\
\text { Langkiau } \\
\text { (U) }\end{array}$ & & & & $\begin{array}{c}0.38 \\
7\end{array}$ & 44.1 & 49.1 & 0.53 & 56 & 53.8 \\
\hline 2 & $\begin{array}{l}\text { Lengan } \\
\text { Sutomo (S) }\end{array}$ & 0.59 & 70.00 & 31.10 & 0.66 & 97.7 & 49.6 & 0.63 & 129 & 41.10 \\
\hline 3 & $\begin{array}{l}\text { Lengan } \\
\text { Sawahan } \\
\text { (B) }\end{array}$ & 1.03 & 199 & 142.9 & 0.66 & 208 & 28.5 & 0.63 & 173 & 33.00 \\
\hline 4 & $\begin{array}{l}\text { Lengan } \\
\text { Andalas (T) }\end{array}$ & 0.58 & 68.00 & 30.90 & 0.66 & 96 & 49 & 0.63 & 94.00 & 47.50 \\
\hline
\end{tabular}

Sumber : Hasil Analisa

penanganan dengan melakukan manajemen dan rekayasa lalu lintas. Adapun strategi-strategi
Dari tabel 8 menunjukaan bahwa terjadi peningkatan kinerja Simpang ketika dilakukan penanganan, seperti pada 
Derajat Kejenuhan, dimana lengan simpang ruas jalan Sawahan sebelum dilakukan perbaikan derajat kejenuhannya 1.03, panjang antrian 199 meter dan tundaaan 142.9 detik/smp). Hal ini menunjukkan bahwa terjadi kemacetan yang parah pada lengan simpang ruas jalan sawahan sehigga berdampak kepada tingginya biaya operasional yang ditanggung oleh pengguna jalan. Berbeda dengan lengan simpang ruas jalan andalas dan lengan simpang ruas jalan sutomo dimana kedua lengan simpang tersebut masih dalam batas normal.

Setelah dilakukan penagananpenanganan dengan melakukan majaemen dan rekayasa lalu lintas maka terjadi peningkatan kinerja dimana pada strategi 1 (pertama) derajat kejenuhannya terjadi peningkatan kinerja dari 1.03 menjadi 0.64 lengan simpang pada ruas jalan sawahan tetapi pada panjang antria terjadi penurunan kinerja dimana sebelum perbaikan 199 meter, sedangkan setelah penganan pada strategi 1 (pertama) sebesar 220 meter. Hal ini dikarenakan adanya penambahan waktu siklus sebesar 120 sehingga menambah waktu antrian pada lampu merah. Namun tundaan kendaraan rata-rata setelah dilakukan penanganan strategi 1 (pertama) terjadi peningkatan kinerja dimana dari 142,9 det/smp sebelum perbaikan menjadi 33 det/smp. Hal ini disebabkan oleh lamanya waktu hijau untuk melepaskan kendaraan dari mulut persimpangan sawahan.

Penanganan yang dilakukan pada strategi 2 (kedua) jauh lebih baik dari penanganan strategi 1 (pertama). Strategi ke-2 (kedua) penanganan yang dilakukan adalah menerapkan pengaturan dengan 3 fase yang dikombinasikan dengan penerapan early cut off pada lengan simpang andalas serta melakukan sterilasi pada kendaaran yang parkir di badan jalan. Dari tabel 6.6 menunjukkan bahwa derajat kejenuhan pada lengan simpang ruas jalan sawahan sebesar 0.63, panjang antrian 173 meter dan tundaan 33 detik, artinya kinerja simpang pada strategi 2 menujukkan peningkatan kinerja dibanding dengan strategi 1 (pertama), Namun pada lengan simpang ruas jalan Andalas terjadi penurunan kinerja pada panjang antrian dimana strategi ke-2 antriannya sebesar 129 meter sedangkan strategi ke-1 sebesar 97 meter. Hal ini disebabkan karena fase pelepasan pada lengan simpang ruas jalan sutomo bersamaan dengan lengan simpang ruas jalan langkiau sehingga arusnya terlawan atau terjadi friksi antar kedua simpangn namun pada tundaan kendaraan rata-rata penanganan strategi ke-2 lebih baik dari penanganan ke-1 dimana tundaan ke-2 sebesar $41.10 \mathrm{det} / \mathrm{smp}$ dan tundaan strategi ke-1 sebesar 49.6. Hal ini disebabkan oleh waktu hijau lengan simpang ruas jalan sutomo pada strategi ke-2 lebih lama dari strategi ke-1.

\section{SIMPULAN}

\section{Simpulan}

Hasil analisis di atas baik disimpulkan bahwa pengaruh beroperasinya Pasar Tradisional dan Pasar Modern (Mall) Simpang Haru pada tahun 2018 sangat signifikan pengaruhnya dalam artian kontribusi bangkitan dan tarikan pengoperasian pasar simpang haru ditambah lagi dengan pertumbuhan kendaraan $3 \%$ pertahun mengakibatkan penurunan kinerja lalu lintas dengan Derajat kejenuhan melebihi dari 1 (satu) Sehingga yang komprehensif untuk mengantisipasi penurunan kinerja persimpangan .

\section{Rekomendasi}

Agar kondisi kinerja lalu lintas tidak mengalami penurunan kinerja yang signifikan akibat beroperasinya Pasar Tradisional dan Pasar Modern (Mall) Simpang Haru maka dapat dilakukan sebagai berikut :

1. Rekayasa Lalu Lintas

a. Memasang Rambu dilarang parkir sebanyak 7 (delapan) unit dengan papan tambahan $(\leftarrow$ $30 \mathrm{~m} \rightarrow$ ), ditempatkan di sisi Kiri dan Kanan Jl. Sawahan, Jl. Sutomo, Jl. Andalas, Jl. Langkiau yaitu sebelum dan sesudah akses keluar masuk dan 1 unit Rambu dilarang parkir dengan papan tambahan $(\leftarrow$ $50 \mathrm{~m} \rightarrow$ ) pada sisi utara dan selatan (lihat gambar)

b. Memasang rambu larangan berhenti sebanyak 8 (sembilan) unit dekat dengan mulut persimpangan (lihat gambar) di Kiri dan Kanan Jl. Jl. Sawahan, Jl. Sutomo, Jl. Andalas, Jl. Langkiau (lihat gambar)

c. Memasang Rambu pemeberhentihan Angkot pada Jalan Sawahan sisi utara dan sisi selatan dan Jalan Langkiau pada sisi timur (lihat gambar)

d. Memasang larangan berputar di median jalan sutomo selanjutnya putaran kendaraan di tugu api simpang haru (lihat gambar)

e. Memasang Rambu perintah arah masuk dan arah keluar dengan papan tambahan di pintu masuk dan pintu keluar Pasar Trasional dan Pasar Modern Simpang Haru

f. Rambu larangan masuk sebanyak 1 (satu) unit ditempatkan di pintu keluar Pasar 
Trasional dan Pasar Modern Simpang Haru pada jalan langkiau

g. Memasang rambu Traffic Ligth pada 4 (empat) mulut perimpangan

h. Memasangan rambu dan marka panah untuk sirkulasi di dalam Pasar Trasional dan Pasar Modern Simpang Haru (sirkulasi arah lihat gambar)

i. Melakukan pengaspalan jalan di ruas jalan langkiau dengan lebar 10 meter panjang 100 meter

j. Memasang marka pemisah lajur pada masing-masing mulut persimpangan kecuali jl. Langkiau

k. Melakukan pemasangan separator pada Ruas Jalan Sawahan sepanjang \pm 90 meter, Ruas Jalan Sutomo sepanjang \pm 70 dan Ruas Jalan Andalas untuk \pm 70 menghindari friksi pada lalu lintas yang berlawan arah sehingga mengurangi gangguan tercepatan serta mengurangi kecelakaan lalu lintas

1. Rambu peringatan hati hati dengan papan tambahan (akses keluar masuk Pasar Modern Simpang Haru bagi pengendara yang melewati dan masuk Pasar Trasional dan Pasar Modern Simpang Haru sebanyak 1 unit pada ruas jalan Sawahan

m. Membuat lay bay (celukan) tempat menaikan/menurunkan penumpang di sisi utara Jl. Sawahan (depan Pasar) atau sisi timur jalan langkiau dengan panjang 10 meter dan lebar 5 meter

n. Memperbesar jari-jari tikungan di lengan persimpangan antara Jl. Sawahan dan Sutomo (dekat Muhammadyiah). Perbaikan geometrik jari-jari tikungan dilakukan apabila upaya manajemen lalu lintas tidak bisa lagi menanggulangi permasalahan belok kiri langsung serta volume belok kiri langsung sudah mengganggu arus yang merging dari arah Andalas

o. Membuat Pos Penjagaan di dekat pintu masuk jalan Sawahan

2. Manajemen Lalu Lintas

a. Melakukan setting lampu lalu lintas sesuai dengan jumlah dan peningkatan arus lalu lintas yang keluar pada mulut persimpangan

b. Pengaturan arus lalu lintas pada mulut persimpangan dilakukan penerapan 3 fase dengan kombinasi early cut off (lihat gambar fase) untuk menghindari konflik terhadap lalu lintas yang menerus dengan kendaraan yang masuk ke Pasar Pasar Trasional dan Pasar Modern Simpang Haru

c. Melakukan setting lampu lintas secara berkala untuk mengantisipasi peningkatan arus lalu lintas

d. Jadwal tayang studio 21 dimulai dan berakhir diluar pada jam sibuk e. Pintu masuk dari arah jalan jalan Sawahan dibuka hanya 1 (satu) pintu pintu masuk, sedangkan untuk pintu keluar menujun jalan sawahan ditiadakan untuk menghindari konflik

f. Pintu masuk dari arah jalan jalan Sawahan dibuka hanya 1 (satu) pintu pintu masuk, sedangkan untuk pintu keluar menujun jalan sawahan ditiadakan untuk menghindari konflik

g. Untuk menghindari penurunan kinerja pada mulut persimpangan maka pada mulut persimpangan Ruas Jalan Sawahan, Sutomo, Andalas dan Ruas Jalan Langkiau kiri jalan terus

h. Pada jam sibuk, kendaraan yang hendak masuk dan keluar Pasar Trasional dan Pasar Modern Simpang Haru khususnya pada Jl. Sawahan harus diatur dengan menempatkan petugas pengatur lalu lintas

i. Untuk loading dan unloading kendaraan barang dilakukan pada malam hari pada saat diluar jam sibuk

j. Petugas keamanan Pasar Tradisional dan Modern membantu petugas PT. KAI untuk mengatur pintu perlintasan pada saat kereta api lewat

\section{DAFTAR PUSTAKA}

Black, J.A. 1981. Urban Transport Planning: Theory and Practice. London: Cromm Helm.

Departemen Pekerjaan Umum Republik Indonesia. 1997. Manual Kapasitas Jalan Indonesia (MKJI). Jakarta.

Keputusan Menteri Perhubungan Nomor 14 Tahun 2006. Manajemen dan Rekayasa Lalu Lintas. Jakarta

Papacostas, C.S. 1987. Fundamental of Transportation Engineering. Prentice Hall Inc, Englewood Cliffs. New Jersey.

Tamin, O.Z. 1997. Perencanaan dan Pemodelan Transportasi, Penerbit ITB, Bandung 


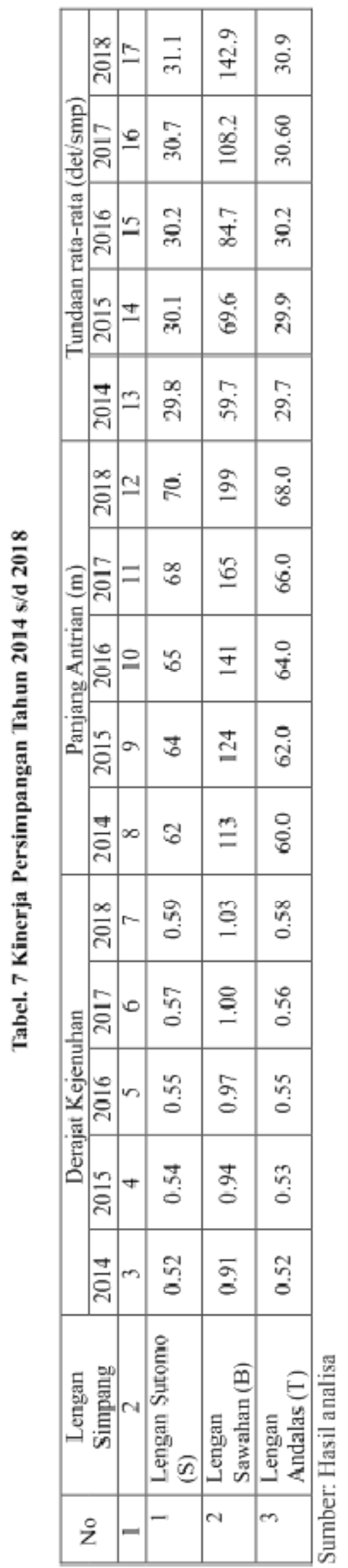

